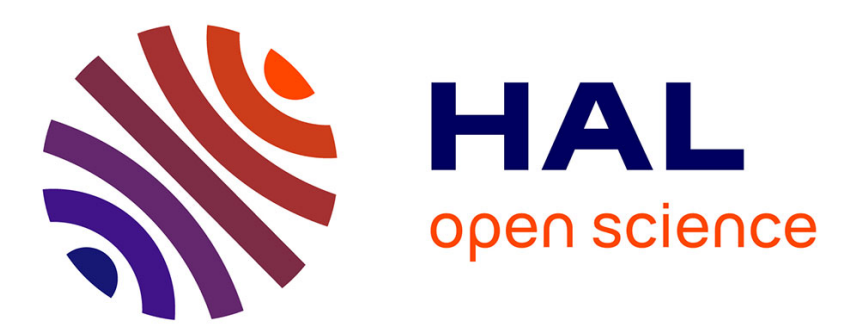

\title{
High Speed Photography of Moire Fringes. Application to Ceramics Under Impact
}

T. Bertin-Mourot, C. Denoual, G. Deshors, P. Louvigné, T. Thomas

\section{To cite this version:}

T. Bertin-Mourot, C. Denoual, G. Deshors, P. Louvigné, T. Thomas. High Speed Photography of Moire Fringes. Application to Ceramics Under Impact. Journal de Physique IV Proceedings, 1997, 07 (C3), pp.C3-311-C3-316. 10.1051/jp4:1997355 . jpa-00255512

\section{HAL Id: jpa-00255512 https://hal.science/jpa-00255512}

Submitted on 1 Jan 1997

HAL is a multi-disciplinary open access archive for the deposit and dissemination of scientific research documents, whether they are published or not. The documents may come from teaching and research institutions in France or abroad, or from public or private research centers.
L'archive ouverte pluridisciplinaire HAL, est destinée au dépôt et à la diffusion de documents scientifiques de niveau recherche, publiés ou non, émanant des établissements d'enseignement et de recherche français ou étrangers, des laboratoires publics ou privés. 


\title{
High Speed Photography of Moire Fringes. Application to Ceramics Under Impact
}

\author{
T. Bertin-Mourot, C. Denoual, G. Deshors, P.F. Louvigné and T. Thomas
}

Département Matériaux en Conditions Sévères, DGA/DCE/Centre de Recherches et d'Études d'Arcueil, 16 bis avenue Prieur de la Côte d'Or, 94114 Arcueil, France

\begin{abstract}
A high speed moiré photography system has been developed for measuring dynamic 2-D strain fields. The method is illustrated by an impact onto tiles of Silicon Carbide to display the history of the strain field. The steel blunt cylinder projectile is fired by a gas gun at a speed of $330 \mathrm{~m} / \mathrm{s}$. A checked grating with 28 lines $/ \mathrm{mm}$ was reproduced on the target lateral surface using aluminum. The moire fringes are recorded during impact by a high speed camera. Sequences of fringe patterns are analyzed by a 2-D Fourier Transform method to obtain the strain fields.
\end{abstract}

Résumé. Une technique de moiré est proposée pour l'étude des déformations de carreaux de carbure de silicium impactés par un projectile en acicr. Ce projectile est propulsé par un canon a gaz à la vitesse de $330 \mathrm{~m} / \mathrm{s}$. Un réseau de 28 lignes/mm en aluminium est photogravé sur la cible et imagé sur un réseau de référence. Une figure de moiré apparait et les évolutions de cette figure sont enregistrées en temps réel par une caméra ultra-rapide. Ces images sont analysées dans le plan de Fourier afin d'obtenir des cartes de déformations.

\section{INTRODUCTION AND EXPERIMENTAL CONTEXT}

Most of the mechanisms initiated during impact (such as nucleation of flaws, propagation and interaction of cracks, stress release) can only be studied during dynamic test, which has to be chosen to give reliable data on the damage initiation and evolution. The use of stress gauges is delicate because interferences with the stress state can occur. The high speed camera pictures provide some indications on the cracking mechanisms but give no information about the strain state and location. The present study deals with an optical method to display strains induced by impact.

Optical techniques to visualize strains on such type of impact have significant advantages over conventional strain gauges: non-contacting measurement, whole-field mapping, micronic sensitivity. Photoelasticity or holographic methods are the two most commonly used techniques for studying quasi-static and dynamic strain fields. Nevertheless, the first one is difficult to use with ceramic materials such as Silicon Carbide. The second one can only be applied for low displacements and is delicate to use for measuring strains induced by impact.

Moiré photography is an alternative technique first developed by Dantu [1] which makes use of the geometric interferences phenomenon that occur when two gratings are superimposed. An example of high resolution moiré photography used is given by Huntley and Field [2] for measuring displacement fields on impacted PMMA and composite plates. The main difficulties to observe ceramic impact lie in the time range and the very high wave velocity (around $11000 \mathrm{~m} / \mathrm{s}$ ). With a simple and mobile moiré optical set-up and a new automated fringe pattern analysis, it is possible to overcome the experimental constraints described above.

\section{HIGH SPEED MOIRÉ PHOTOGRAPHY}

When periodic structures are superimposed, a pattern with new periods (beats) appears in addition to those of the individuals grids (Fig. 1). The pattern corresponding to this new beats are the moire fringes. The distance $f$ between two moiré fringes can be written as (see Fig. 1) 


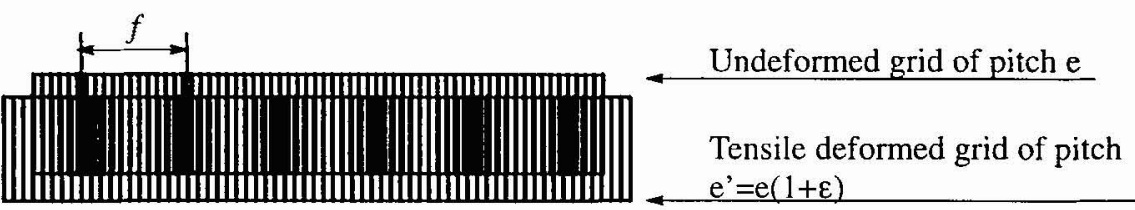

Fig. 1. Moiré pattern with a uniform tensile strain.

$$
f=\left|\frac{e}{\varepsilon}\right|
$$

where $e$ represents the initial pitch of the grid and $\varepsilon$ the subsequent strain. Before any dynamic straining, the reference grating is slightly enlarged to generate an initial fringe pattern of $f$ spaced parallel lines (carrier fringes). If a dynamic strain $\varepsilon$ appears, $f$ is increased by $\Delta f$ and becomes $f^{\prime}$. The increment $\Delta f$ is given by the definition of the acquisition set-up and defines the minimal readable strain $\varepsilon$

$$
\varepsilon=e \frac{f^{\prime}-f}{f f^{\prime}}=e \frac{\Delta f}{f^{2}-f \Delta f}
$$

If the minimum strain $\varepsilon$ and $\Delta f$ are known, Eqn. (2) allows to evaluate the reference grating pitch. The minimum readable strain increases when $f$ and $f$ increase (i.e. the distance between two fringes increases) but the geometrical resolution decreases. A good compromise can be obtained with $\mathrm{e}=28 \mu \mathrm{m}, f=1.7 \mathrm{~mm}$ and $\Delta f=0.1 \mathrm{~mm}$ so that the minimum readable strain is $\varepsilon=7.10^{-4}$.

The grating is reproduced on the ceramic by aluminum vapor deposition, resulting in a good contrast. This checked deposit can be described as the superposition of two grid lines at $\pm 45^{\circ}$ and allows a $2 \mathrm{D}$ displacement analysis. Information on the two directions can then be simultaneously extracted, which is essential when the event is not reproducible. The optical set-up used in the experiment is shown in Fig. 2. The specimen grating (SG) is imaged by a Nikkor ED macro $\mathrm{f}=200 \mathrm{~mm} \mathrm{f} / 4$ objective lens (L3) onto the reference grating ( $\mathrm{RG}$ ) at a magnification 1:1. The moiré pattern appears in the reference grating plane (RG) and is imaged through the camera $60 \mathrm{~mm}$ Nikkor macro lens (L1) onto the photocathode plane. A field lens $(\mathrm{L} 2, \mathrm{f}=125 \mathrm{~mm})$ is used to image the A2 iris onto the A1 iris, resulting in a uniform contrast in the film plane. The out-of-plane strain of the ceramic (several microns) is assumed not to modify the moiré pattern and can be neglected. The use of a field lens requires an objective lens aperture larger than that of the camera in order to image the entire target field. The light source is a powerful $(8.6 \mathrm{MW})$ xenon flash lamp that produces a light flux during $20 \mu$ s without any orientation constraint because of the scattering power of the target surface. The checked moire pattern resulting from the superposition of the two gratings is well contrasted but has a lens aberration which can be extracted by image processing as shown below.

All the optical bench is compact and a micrometric adjustment is applied to each bench components (including the target), resulting in a very precise and simple optical set-up (Fig. 3). The camera used for this study is an Ultranac FS 501 (IMCO) camera capable of providing a sequence of framing images at speeds up to twenty frames per micro-seconds with a time exposure of at least 10 nanoseconds. The camera is triggered by a short-circuit via a TTL input. The xenon flash is triggered by the TTL camera

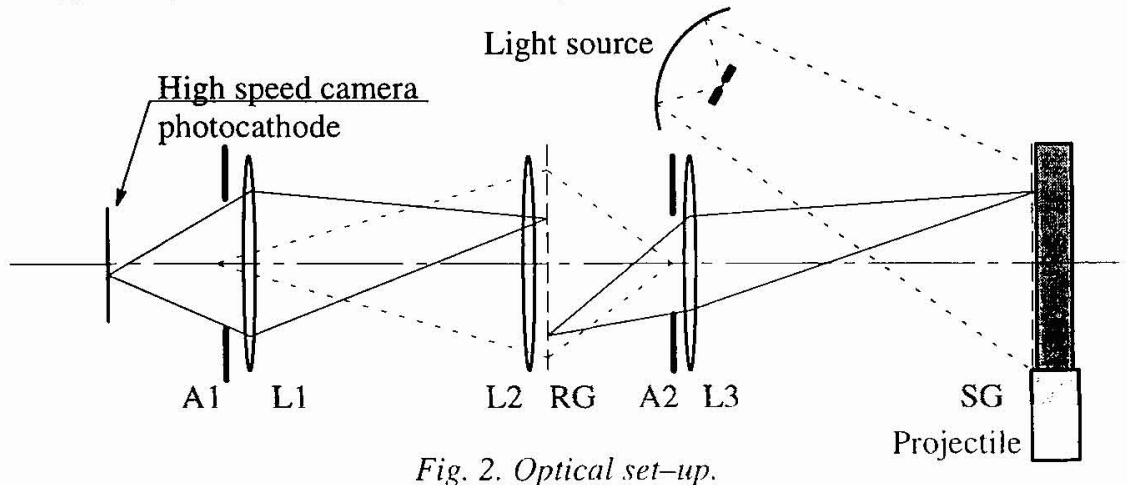

Fig. 2. Optical set-up. 


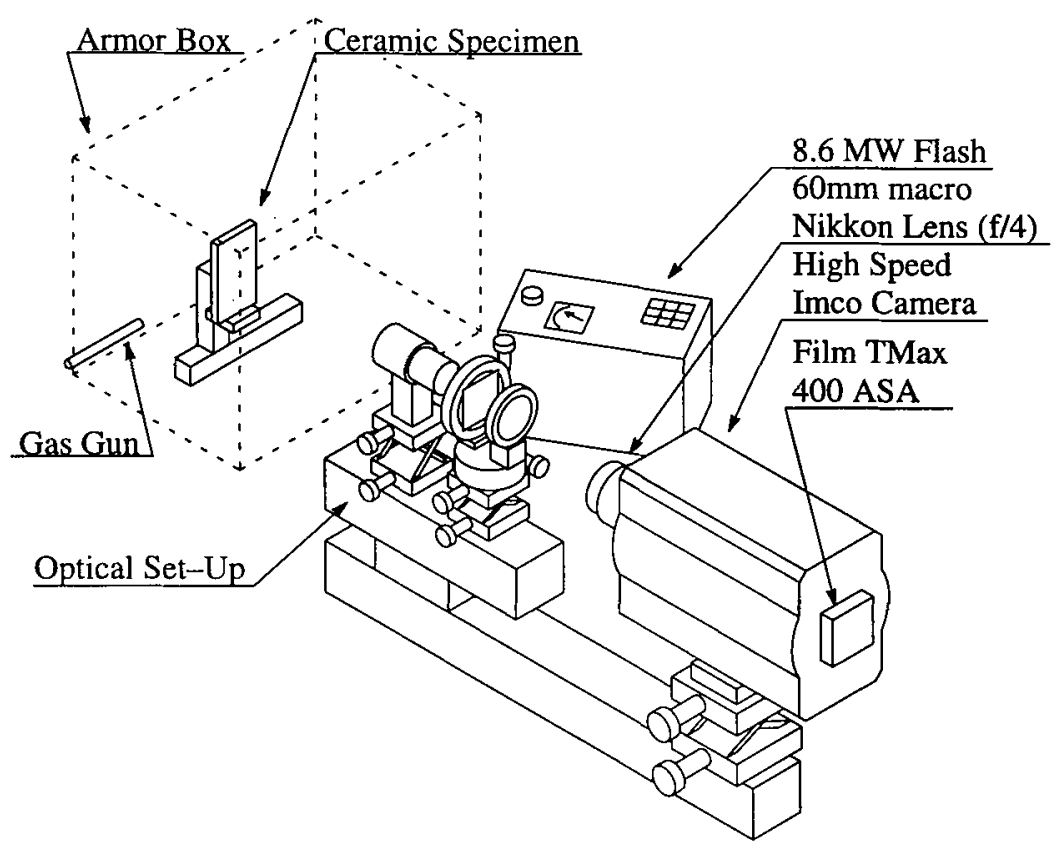

Fig. 3. Experimental Set-Up.

output with a delay. This short-circuit is put in front of the target edge at a distance depending on the projectile velocity and the flash rise time $(5 \mu \mathrm{s})$. It is composed of steel wires $63 \mu \mathrm{m}$ in diameter disposed in a very tight grid form so that the impact surface is not disturbed. The projectile (a steel blunt cylinder $11 \mathrm{~mm}$ in diameter and $20 \mathrm{~mm}$ long) is fired by a high pressure light gas gun at a speed of $330 \mathrm{~m} / \mathrm{s}$. The camera records sequences of 12 frames on single $127 \times 102 \mathrm{~mm}$ sheets of Kodak TMAX 400 ASA film, push processed to 1600 ASA. All parameters (number of frames, time exposure, flash delay, etc.) are set by a PC.

\section{FRINGE PATTERN ANALYSIS}

Useful quantitative information can be easily obtained from a checked moire pattern. For example, the strain at a few points can be calculated by measuring the local fringe spacing using Eqn. (1). The technique of partial sum extraction in the Fourier expansions are among the most powerful methods to compute the strains in the whole moiré pattern. The analysis is based on a 2-D version of the Takeda Fourier method [4].

The Fourier transform of a pseudo-periodic pattern such as moiré fringes contains localized peaks which indicate a pronounced periodicity in the object. The vector joining the center of the transform pattern and those peaks gives the main directions of the pseudo-periodic pattern. The spatial frequency is proportionally related to the magnitude of this vector. The carrier fringe of a checked moire pattern can be written as the sum of two cosine functions in the two principal directions $\mathrm{X}$ and $\mathrm{Y}$. It follows a general intensity distribution

$$
i(x, y)=a_{o}(x, y)+a_{X}(x, y) \cos \left(\phi_{X}(x, y)\right)+a_{Y}(x, y) \cos \left(\phi_{Y}(x, y)\right)
$$

or with Euler notations

$$
i(x, y)=a_{o}(x, y)+\frac{1}{2}\left[a_{X}(x, y)\left(e^{i \phi_{X}(x, y)}+e^{-i \phi_{X}(x, y)}\right)+a_{Y}(x, y)\left(e^{i \phi_{Y}(x, y)}+e^{-i \phi_{Y}(x y)}\right)\right]
$$

where $a_{o}$ represents the variation of background intensity, $a_{X}$ and $a_{Y}$ depend on the fringe contrast. The functions $\phi_{x}(\mathrm{x}, \mathrm{y})$ and $\phi_{y}(\mathrm{x}, \mathrm{y})$ are the so called phases of the periodic pattern and contain the information about the displacement of the fringes. Equation (4) can be rewritten in the Fourier plane 


$$
I(\mu, v)=A_{o}(\mu, v)+A_{X}(\mu, v)+A_{Y}(\mu, v)+\left[A_{X}(\mu, \nu)+A_{Y}(\mu, v)\right]^{*}
$$

where $\mu$ and $v$ are the spatial frequencies in the directions $\mathrm{X}$ and $\mathrm{Y}$, respectively, and the star denotes the complex conjugate. The functions $A_{X}$ and $A_{Y}$ are localized around the carrier frequencies of the fringes in both directions. The variation of the background intensity is small compared to the fringes spatial variation. It follows that the functions $A_{0}, A_{X}, A_{X}{ }^{*}, A_{Y}$ and $A_{Y} *$ cannot overlap. The inverse Fourier transform can then be performed on only one of them, (e.g. $\left.A_{x}\right)$

$$
i_{X}(x, y)=\frac{1}{2} a_{X}(x, y) e^{i \Phi_{X}(x, y)}
$$

The phase functions $\phi_{\mathrm{x}}(\mathrm{x}, \mathrm{y})$ or $\phi_{\mathrm{y}}(\mathrm{x}, \mathrm{y})$ can be extracted from the Fourier transform by selecting the peaks $A_{X}$ or $A_{Y}$ with

$$
\Phi_{X}(x, y)=\tan ^{-1}\left[\frac{\operatorname{Im}\left(i_{X}(x, y)\right)}{\operatorname{Re}\left(i_{X}(x, y)\right)}\right] ; \Phi_{Y}(x, y)=\tan ^{-1}\left[\frac{\operatorname{Im}\left(i_{Y}(x, y)\right)}{\operatorname{Re}\left(i_{Y}(x, y)\right)}\right]
$$

where $\mathrm{Re}$ and $\mathrm{Im}$ denote the real and imaginary parts of a complex number. The phase values given by Eqn. (7) lie between $-\pi / 2$ and $\pi / 2$. When the magnitude change is greater than $\pi / 2$ between adjacent data point, $\pi$ is either added or subtracted (unwrapping), depending on the sign of the change. Those two phases are related to the relative displacement components $D_{x}$ and $D_{y}$ by

$$
D_{X}(x, y)=e \frac{\Phi_{X}(x, y)}{2 \pi} ; D_{Y}(x, y)=e \frac{\Phi_{Y}(x, y)}{2 \pi}
$$

Static and dynamic frames are digitized directly from the film. The two components of displacements are extracted from each images by calculating the phase at each pixel according to Eqn. (7). After unwrapping, relative displacements in statics $\left(\mathrm{D}_{\text {static }}\right)$ and dynamics $\left(\mathrm{D}_{\text {dynamic }}\right)$ are subtracted to get rid of the fictitious displacements and the optical aberrations introduced by the initial deformation (see Eqn. (2)). Deformations are then calculated by partial differentiation of $D_{x}$ and $D_{y}$.

An application of the high speed moire photography is presented for an impact with a hard steel blunt projectile onto a silicon carbide ceramic tile $\left(10 \times 50 \times 100 \mathrm{~mm}^{3}\right)$. The velocity of the impactor is equal to $330 \mathrm{~m} / \mathrm{s}$. A set of twelve frames has been recorded. The first frame is recorded before any physical contact, is free of constrains and constitutes the reference moire pattern. The dynamic response of the specimen is recorded on eleven frames from $1 \mu$ s to $6.5 \mu$ s after impact with a 500 ns interframe time and a 40 ns exposure time. A typical result is presented in Fig. 4. The fourth frame of the whole sequence shown in Fig. 4-a shows a strain due to the impact (on the left part of the picture) plus a fictitious strain due to the optical set-up aberration. The FFT method cannot give reliable data when the moire fringes are blurred. To overcome this problem, the artefacts generated during the fringe pattern analysis are automatically reset to zero in a zone colored in gray in Fig. 4.

It can be noticed that the second principal strain reaches an important value before any significant evolution of the first principal strain. This is consistent with a cylindrical stress wave geometry in which the tensile strain is induced by the radial motion of the material. Moreover, the cylindrical stress wave geometry hypothesis is corroborated by the strain eigen vector direction. The analysis of the $2^{\text {nd }}, 3^{\text {rd }}$, $4^{\text {th }}$ and $5^{\text {th }}$ frames of this sequence are presented in Fig. 5. The celerity of the shock wave can be evaluated from those frames and is on the order to $11150 \mathrm{~m} / \mathrm{s}$, which is a classical value for Silicon Carbide [3]. Those data can be used to analyze the behavior of hard materials submitted to strain rates up to $10^{4} \mathrm{~s}^{-1}$.

\section{CONCLUSION}

A high speed moiré photography system has been developed to measure the strain states induced by impact of a hard steel projectile on a ceramic tile. The first advantage lies in a direct measure of the specimen displacements without calibration. The second one is a measurement without any interferences with the stress waves. The optical set-up and light source are compact, resulting from a fast optical configuration. Sequences of fringe patterns are analyzed by a 2-D Fourier Transform method to obtain the strain fields. The shock wave and the induced tension are clearly readable with a good accuracy. 

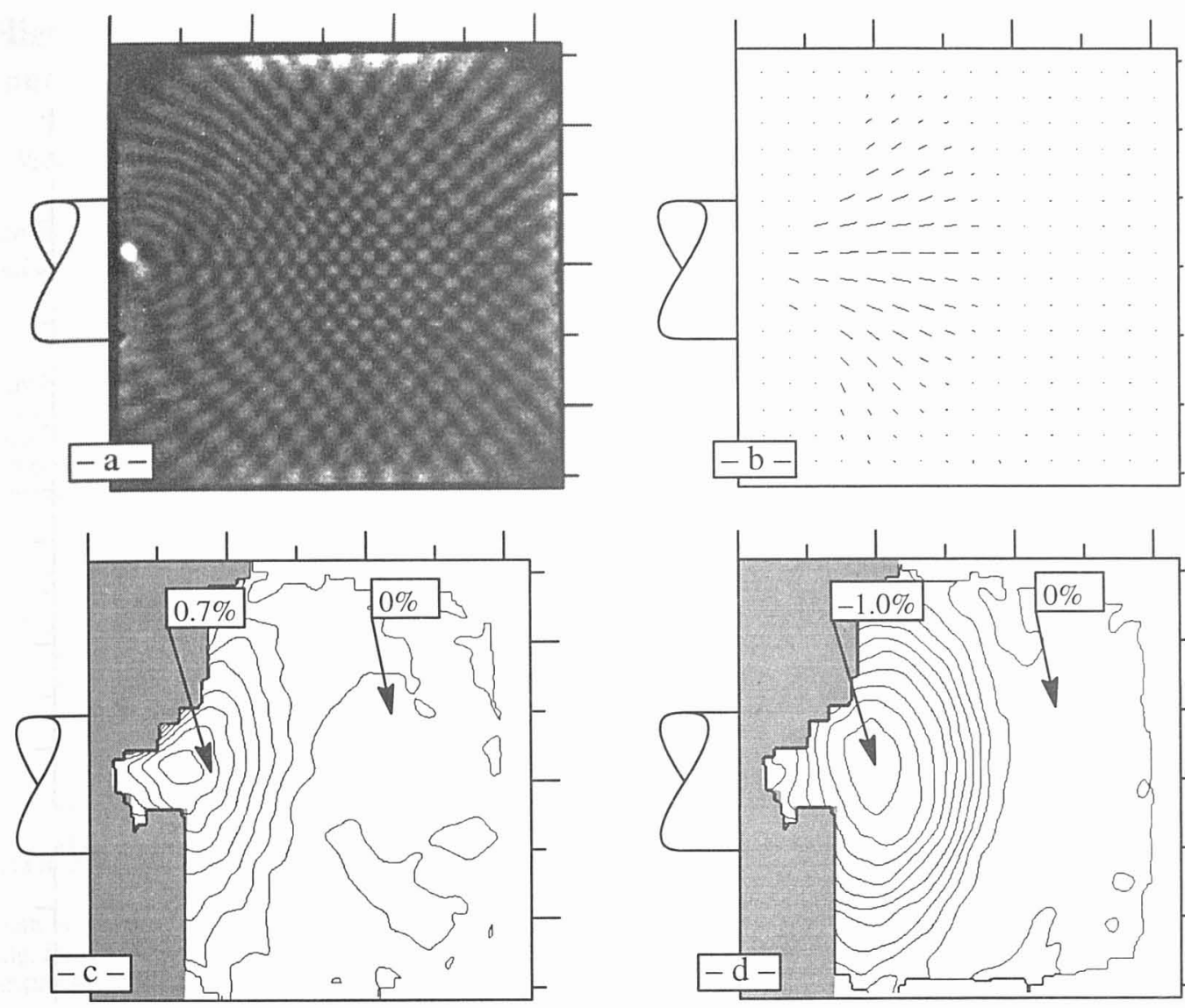

Fig. 4. A typical example of strain fields $2 \mu$ s after impact. a) The initial frame. b) Second (negative) eigen strain direction. The magnitude is related to the second eigen strain amplitude. c) and d): First and second eigen strains plotted with a $0.1 \%$ step between each curve. N.B. no data available in the gray zone.

\section{ACKNOWLEDGMENT}

This work was supported by DGA/DCE.

\section{REFERENCES}

[1] Dantu P. "Utilisation des réseaux pour l'étude des déformations", Annales de l'institut technique du bâtiment et des travaux publics, 121, (1958), pp. 78-98.

[2] Huntley J.M., Field J.E. "High Resolution Moiré Photography: Application to Dynamic Stress Analysis", Optical Engng., 28 (8), (1989), pp. 926-933.

[3] Riou P. "Contribution à l'étude de l'endommagement du Carbure de Silicium lors d'un impact basse énergie". PhD Dissertation, (1996), Ecole Nationale Supérieure des Mines de Paris.

[4] Takeda M., Ina H., Kobayashi S. "Fourier-Transform Method of Fringe-Pattern Analysis for Computer--Based Topography and Interferometry", J. Opt. Soc. Am., 72 (1), (1982), pp. 156-160. 
a) First principal strain

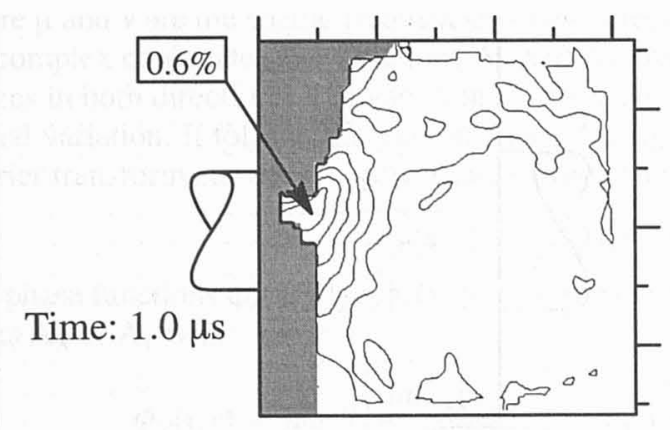

Time: $1.5 \mu \mathrm{s}$
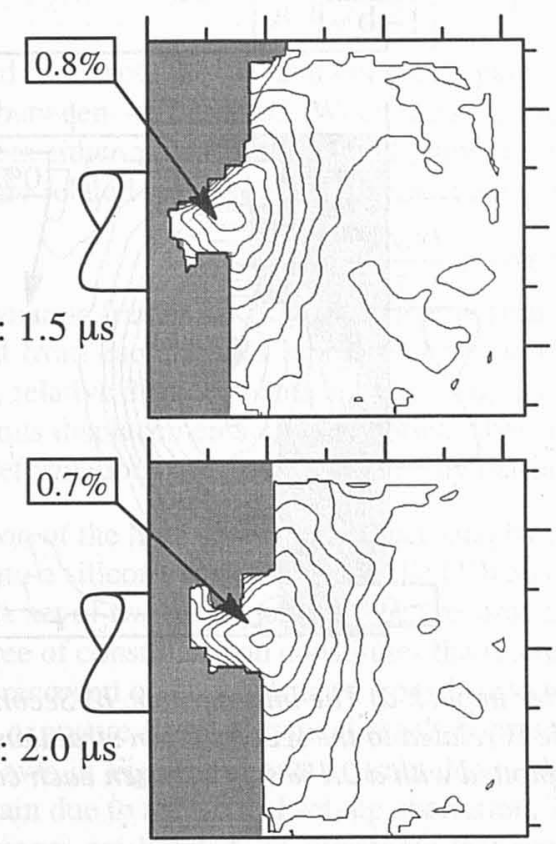

Time: $2.0 \mu \mathrm{s}$

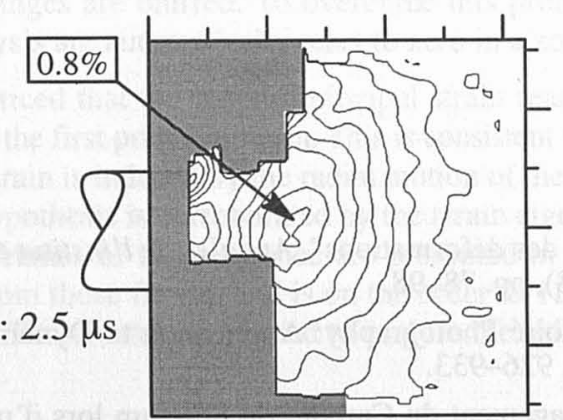

Time: $2.5 \mu \mathrm{s}$ b) Second principal strain
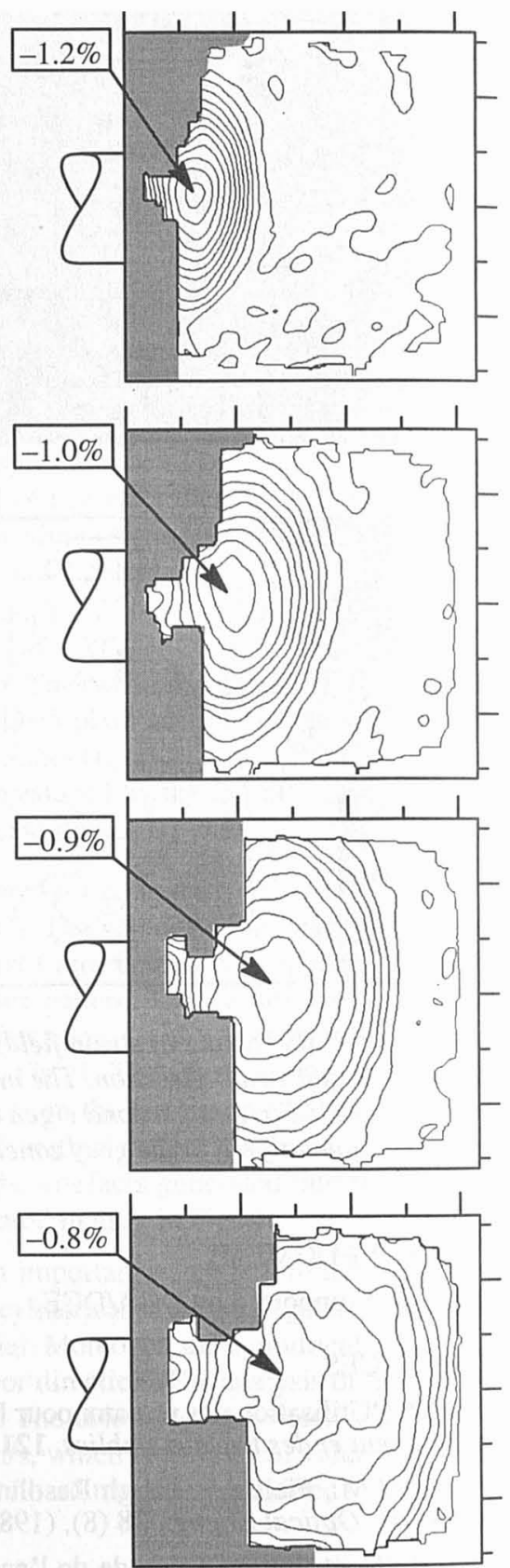

Fig. 5. Fringe Pattem Analysis. The projectile velocity is $330 \mathrm{~m} / \mathrm{s}$. The $2^{\text {nd }}, 3^{\text {rd }}$, $4^{\text {th }}$ and $5^{\text {th }}$ frame among the 12 acquired frames are plotted with a $0.1 \%$ step between each curve. a) Maximum Principal Strain Field: tension induced by the compressive wave is shown. b) Minimum Principal Strain Field: the first compressive wave is clearly visible. N.b. no data available in the gray zone. 